\title{
MEDIDAS PREVENTIVAS DE CUSTOS DE TRANSAÇÃO NOS ESCRITÓRIOS CONTÁBEIS DE NOVA MUTUM - MT
}

\author{
TRANSACTION COSTS PREVENTIVE MEASURES IN ACCOUNTING FIRMS AT \\ NOVA MUTUM - MT (BRAZIL)
}

\author{
Nome: Ana Caroline Scotton \\ Instituição: Universidade do Estado de Mato Grosso (UNEMAT) \\ Nome: Laércio Juarez Melz \\ Instituição: Universidade do Estado de Mato Grosso (UNEMAT) \\ E-mail: laercio@unemat.br - https://orcid.org/0000-0003-1125-1895
}

\section{RESUMO}

Esse trabalho tem como objetivo identificar quais as medidas utilizadas pelos escritórios de contabilidade de Nova Mutum para prevenção dos custos de transação. A realização da pesquisa se deu por meio de questionário auto aplicado, com caráter qualitativo e descritivo. A amostragem foi não probabilística por conveniência. Foi possível identificar que os escritórios não costumam revisar seus contratos, a menos que haja mudanças no regime tributário e no plano econômico. As principais formas de prevenção de custos ex post são confirmação por emails e protocolos. Na prevenção de custos estabelecidas em contrato os escritórios optam por incluir salvaguardas como cláusulas de indenização, além de monitoramento para verificação do cumprimento dos contratos e reuniões com os clientes. Os participantes da pesquisa concordam que há presença de oportunismo em alguns de seus clientes e que o ambiente não é de grande incerteza, sendo este o motivo para baixa frequência na revisão de seus contratos. Palavras-chave: Ciências Contábeis. Economia dos Custos de Transação. Contratos.

\begin{abstract}
This paper aims to identify which measures are taken by Nova Mutum's accounting firms to prevent transaction costs uses. The research was carried out using self-applied questionnaire with a qualitative and descriptive structure. The sampling was not probabilistic by convenience. It was possible to identify that the offices do not usually revise their contracts, unless there are changes in the tax regime and the economic plan. The main forms of ex post cost prevention are email and protocol confirmation. In order to prevent contract costs, offices choose to include safeguards such as indemnity clauses, as well as monitoring to verify compliance with contracts and meetings with clients. Survey participants agree that opportunism is present in some of their clients, and that the environment is not of great uncertainty, which is why they often have low contract reviews
\end{abstract}

Keywords: Transaction Costs. Preventive measures. Accountancy. 1 INTRODUÇÃO

Os custos de transação são custos relacionados às transações entre empresas quando esta estabelece relações contratuais com o mercado, portanto, são os custos de negociar, redigir 


\section{Revista \\ UNEMAT de \\ Contabilidade}

v. 10, n. 19,2021

e garantir o estabelecido em um contrato (FIANI, 2002). Os custos de transação podem acontecer em momentos distintos, sendo classificados em custos ex ante e ex post (WILLIAMSON, 2012).

Com o decorrer do tempo as transações foram ficando cada vez mais complexas e providas de incerteza, visto isso, a hierarquia surgiu de modo fundamental para regular esses tipos de transações, então a organização, surge como uma resposta para ambientes incertos (CÁRDENAS; LOPES, 2006). A abordagem dos custos de transação mostra a importância das instituições para a análise econômica, tendo em vista que mercados crescentemente incompletos e imperfeitos tem como resultado a ocorrência de custos maiores (North, (2006 apud PEREIRA et al., 2014).

Williamson (1985) baseado em Coase (1937) foi precursor da teoria dos custos de transação. Williamson afirma que há pressupostos que fazem com que os custos de transação ocorram, como: oportunismo e racionalidade limitada, (WILLIAMSON, 2012), e traz à tona a importância dos atributos ex post (ZYLBERSZTAJN, 1995). Se a capacidade cognitiva fosse ilimitada, os acordos poderiam prever quaisquer circunstancias futuras e por conta disso as transações são caracterizadas pela incerteza, especificidade de ativos e por sua frequência (FIANI, 2003).

As pesquisas de Borges et al. (2012), Santos et al. (2011) e Silva e Brito (2013), procuraram identificar as medidas preventivas de custos de transação entre os escritórios de contabilidade. Borges et al. (2012) identificaram que os escritórios tentam prevenir os custos de transação por meio de reuniões formais, investimentos em capacitação de seus funcionários e alterações de cláusulas contratuais. Santos et al (2011) identificou que as principais medidas utilizadas, são protocolos recibos simples, recibos eletrônicos, comunicações por e-mails e inclusão de cláusulas contratuais de permanência mínima. Silva e Brito (2013) concluíram que a análise dos efeitos dos constructos de incerteza, racionalidade limitada e especificidade de ativos revelou que os coeficientes gerados explicam a ocorrência do comportamento oportunista. No mesmo sentido dos trabalhos propostos anteriormente, esta pesquisa busca incrementar os dados sobre medidas de prevenção de custos de transação, visto isso, $o$ problema proposto é: quais as medidas que os escritórios de contabilidade de Nova Mutum utilizam para prevenir custos de transação?

Buscando especificamente: 1) identificar as características dos escritórios participantes; 2) verificar a presença dos pressupostos comportamentais de oportunismo e racionalidade limitada na visão dos contadores; 3) identificar quais fatores mais influenciam os escritórios a utilizar medidas preventivas dos custos de transação.

Os custos de transação têm importância significativa devido à dificuldade de mensuração, devido a não previsibilidade de sua ocorrência e por se tratarem de custos de manutenção, revisão e ajustes contratuais, custos ex-post, partindo do ponto de que o comportamento das pessoas influenciam, devido aos pressupostos comportamentais, (BORGES et al., 2012; SILVA; BRITO, 2013). Conhecer as medidas preventivas utilizadas pelos escritórios em Nova Mutum e compará-las a outros trabalhos já realizados e se forem efetivas permitirá que outros escritórios, inclusive de outros setores, adaptem as medidas apontadas a seus contratos, podendo também identificar como ocorrem esses custos e orientar qual a melhor estrutura de governança: fazer, optar pelo mercado, ou elaboração de contratos. 


\section{Revista

\section{REFERENCIAL TEÓRICO}

O referencial teórico apresenta três partes. Na primeira são apresentados os conceitos fundamentais da Economia dos Custos de Transação (ECT). Na segunda são apresentados os pressupostos comportamentais e características das transações que suportam a ECT. Na terceira parte são apresentados os principais serviços que os contadores oferecem aos seus clientes, que são oferecidos na transação.

\subsection{Economia dos Custo de transação}

Para Fiani (2002), os custos de transação são os custos enfrentados pelo agentes quando esses estabelecem relações com o mercado, sendo assim custos de negociar, redigir e garantir o execução de um acordo. Os custos de transação se diferem dos custos de produção, os custos de transação são os equivalentes ao atrito dos sistemas físicos, a economia dos custos de transação alega o problema de contratação como sendo o problema da organização econômica (WILLIAMSON, 2012).

Os custos de transação referem-se a atritos do mundo real que impedem negociações a um valor baixo. $\mathrm{O}$ custo de transação define como o acordo foi realizado e o contrato evidencia $\mathrm{o}$ resultado da negociação entre os agentes, portanto, sendo importante para a tomada de decisão (ZYLBERSZTAJN; SZTAJN, 2002).

No horizonte temporal, os custos de transação podem ser divididos em custos ex ante e ex post. Ex ante são custos da elaboração dos contratos, redigir, negociar e salvaguardar. As salvaguardas ex ante podem ser adaptadas, para sinalizar compromissos e restaurar a integridade do contrato, sendo o custo de negociação e de salvaguardas criadas em um acordo. "A maioria dos custos sobre transação pressupõe leis eficazes para litígios contratuais estão em vigor e são executadas pela justiça , de forma que, informada, justificada e de baixo custo" (WILLIAMSON, 2012, p. 17). Ainda de acordo com o autor, na economia dos custos de transação é impossível concentrar todas as ações para uma negociação no estágio ex ante, sendo a negociação generalizada e sendo os atributos comportamentais complexos. Os custos ex ante acontecem antes de a transação ser concretizada, são custos envolvidos na preparação contratual, na negociação entre os agentes e na prevenção de danos relativos ao contrato (FIANI, 2002).

Os custos ex-post ocorrem na duração do contrato, quando este se encontra incompleto em uma situação que não havia sido prevista, sendo, os custos de renegociação, de monitoramento do contrato e de adaptação ao ambiente. (SANTOS; CALÍOPE; COELHO, 2014).

Os custos de transação podem assumir algumas formas, sendo elas: 1) custos de má adaptação incorridos quando as transações saem do alinhamento da curva de contrato de alinhamento, Masahiko Aoki (1983 apud (WILLIAMSON, 2012)); 2) custo de negociação incorridos para corrigir desalinhamentos ex post; 3) custos com a instalação de funcionamento de estruturas de governança; 4) custos da criação de vínculos seguros para fixação de acordos (WILLIAMSON, 2012). Os custos de transação ex post decorrem da necessidade de ajustes e adequações advindos de falhas e erros contratuais (WILLIAMSON, 1996).

Ambos os custos ex ante e ex post são de difícil mensuração, porém essa dificuldade é enfraquecida pelo fato de que os custos de transação são avaliados de forma comparativa, onde uma forma de contrato é comparada a outra, observando assim a sua diferença (WILLIAMSON, 2012). 


\section{Revista UNEMAT de Contabilidade}

Alguns pressupostos são determinantes para a existência dos custos de transação sendo estas a racionalidade limitada (capacidade cognitiva) e oportunismo, onde esses tem características que os fundamentam sendo complexidade e incerteza, e especificidade de ativos (FIANI, 2002).

\subsection{Racionalidade limitada}

Williamson (2012), diz que os custos de transação caracterizam a natureza humana pela referência à racionalidade limitada e ao oportunismo. Para Melz e Marion Filho (2014b) demonstra a impossibilidade do ser humano em prever situações que ainda não ocorreram. Para Miranda et al.(2001, p. 5) "A racionalidade limitada postula que os agentes têm um comportamento otimizador, mas por ser limitada, não conseguem otimização completa, conferindo aos contratos um caráter incompleto". Zylbersztajn (1995) explica que a racionalidade limitada é um pressuposto que está de acordo com o comportamento otimizador, ou seja, o agente econômico deseja otimizar, porém não o consegue.

\footnotetext{
A economia dos custos de transação reconhece que a racionalidade é limitada e sustenta que ambas as partes da definição deveriam ser respeitadas. Uma orientação de economização e suscitada pela parte da definição relativa a racionalidade intencional, enquanto o estudo das instituições é encorajado pela aceitação de que a competência cognitiva é limitada (WILLIAMSON, 2012, p. 41) .
}

Simon (1957, p. xxiv apud (SILVA; BRITO, 2013), traz que o ser humano é intencionalmente racional, no entanto, de forma limitada, pois a mente humana apresenta habilidade limitada de processar informação (SILVA; BRITO, 2013). As limitações cognitivas possuem fundamentos neurofisiológicos, pois há limitação da capacidade de acumular e processar informações e de linguagem, isto limita a capacidade de transmitir informações. Se a racionalidade fosse ilimitada seria possível a inserção de clausulas que preveriam quaisquer circunstâncias (FIANI, 2002).

Ainda de acordo com Fiani (2002), a racionalidade limitada só se torna relevante em um cenário onde podem ser considerados condições de complexidade e incerteza . Logo a racionalidade limitada é a limitação cognitiva de uma parte em prever as possíveis ações oportunistas da outra parte em uma transação (WILLIAMSON, 2012) o que evidencia a importância dos atributos ex post (ZYLBERSZTAJN, 1995).

Com um cenário de racionalidade limitada, um ambiente complexo e a presença de incerteza há condições favoráveis para que os agentes possam adotar comportamentos oportunistas (FIANI, 2002). De acordo com Williamson (2012) e Zylbersztajn (1995), o pressuposto de oportunismo trata do auto interesse, que se refere a revelação incompleta ou distorcida da informação, visando enganar, distorcer disfarçar ou confundir. O problema da organização econômica se dá a partir do momento no qual a propensão ao comportamento oportunista varia entre os entes da população contratante. "O oportunismo está essencialmente associado com à manipulação de assimetrias de informação visando apropriação de fluxos de lucro"(FIANI, 2002, p. 70).

Tendo em vista que os contratos são, em decorrência da racionalidade limitada dos agentes, incompletos ou falhos (WILLIAMSON, 1985; ZYLBERSZTAJN; SZTAJN, 2002) existem, oportunidades para o comportamento oportunista no decorrer da sua modificação, (WILLIAMSON, 1993). 


\section{Revista

\subsection{Oportunismo}

O oportunismo é a busca do auto interesse (WILLIAMSON, 2012). A possibilidade de que possa haver oportunismo já é suficiente para inclusão de salvaguarda em relações contratuais, o que por consequência causa maiores custos de transação (MIRANDA et al., 2001).

Contudo, há ainda outra forma de oportunismo, na qual o auto interesse pode ser buscado de forma não oportunista. Oportunismo parte da premissa de barganha não cooperativa, em que um agente possa deter uma informação a qual outro não possua acesso, assim podendo usufruir de benefícios (ZYLBERSZTAJN, 1995). Fiani (2002) traz que o oportunismo apresenta sentido diverso do utilizado normalmente onde esse comportamento "oportunista" pode ser a expressado como a habilidade de identificar e explorar possibilidade de ganho, oferecidas pelo ambiente.

Apesar de oportunismo remeter a ideia de que comportamentalmente todo ser humano pode agir de maneira oportunista, deve-se ressaltar que não significa que sempre agirão dessa maneira, porém, apenas por haver a possibilidade de algum o fazer, deixaria os contratos expostos a ações que exigem cuidado (ZYLBERSZTAJN, 1995).

Por meio desses dois pressupostos comportamentais tem-se a base de sustentação para a existência dos custos de transação e por consequência, a estrutura de governança ideal para a realização de uma transação específica (MILGROM; ROBERTS, 1992, p. 592).

A transação é caracterizada por: 1) frequência, define a recorrência das transações; 2) o risco, gerenciamento de riscos levando em consideração a variação dos preços associados ao oportunismo dos agentes; 3) especificidade de ativos, recursos limitados a determinadas transações (ZYLBERSZTAJN, 1995).

\subsubsection{Frequência}

A frequência da transação diz respeito à recorrência com que esta ocorre, no que diz respeito a frequências deve-se observar pontos como: (1) quanto maior a frequência de uma mesma transação, maior o relacionamento entre os agentes; (2) quanto maior a frequência, mais fácil é a distribuição, assim maior a mitigação dos custos associados a ela, em várias transações (FARINA; AZEVEDO; SAES, 1997).

Ambientes simples, mesmo com racionalidade limitada, não oferecem dificuldades, porque as restrições de racionalidade limitada dos agentes não são atingidas. Em ambientes complexos a descrição da arvore de decisões pode se tornar extremamente custosa, impedindo os agentes de especificar antecipadamente o que deveria ser feito a cada circunstância (FIANI, 2002, p. 270).

O custo de estrutura de governança (mercados, estruturas híbridas e as hierarquias empresas) é mais fácil de ser tratada se os custos decorrentes de grandes operações que acontecem de modo frequente (WILLIAMSON, 2012).

\subsubsection{Complexidade, risco e incerteza}

A complexidade está relacionada ao contexto na qual está inserida, em ambientes mais complexos as decisões podem ter custos mais altos que em ambientes menos complexos, devida a dificuldade de se prever as situações que possam ocorrer (FIANI, 2002). Quando 


\section{Revista \\ UNEMAT de \\ Contabilidade}

v. 10, n. 19,2021

influenciada pela instabilidade econômica e pelo comportamento dos agentes, a incerteza eleva a complexidade da transação (SARTO; ALMEIDA, 2015).

O risco refere-se a forma pela qual há a distribuição dos resíduos entre os agentes envolvidos na transação. $\mathrm{O}$ risco associado à existência de premissa de oportunismo acarreta custos às transações que ocorrem no mercado, levando a estruturação de formas de governança alternativas (ZYLBERSZTAJN, 1995).

De acordo com Fiani (2002), alguns autores definem incerteza como sendo a possibilidade de identificação de todos os eventos que possam ocorrer, podendo atribuir probabilidade a estes eventos, assim como o risco, outros porem, definem como a incapacidade de prever os eventos que possa vir a acontecer nesse caso as consequências da incerteza serão aplicadas com mais intensidade do que risco. Nogueira (2003 apud Santos; Calíope; Coelho, 2014), diz que trata-se da condição em que os resultados futuros de uma transação não podem ser identificados, criando uma circunstância que se difere do risco sendo associado a possibilidades de probabilidades possíveis de eventos.

\subsubsection{Especificidade de ativos}

Para Fiani (2002), ativos são investimentos feitos pela firma para realizar transações, são ativos desenvolvidos para um fim determinado onde geralmente já há comprador especifico. Ainda segundo o autor são as transações que ocorrem sem frequência definida ou em pequenos números, a problemática é que uma vez investido em ativo específico, o comprador e vendedor passam a ter um relacionamento de forma exclusiva.

Se o fornecedor de determinados bens ou produtos for o único a produzi-los da maneira essencial para determinado comprador os agentes envolvidos (comprador e fornecedor) estarão ligados, já que é o comprador exclusivo desse bem e assim como o fornecedor também o produz com exclusividade de acordo com o necessário ao seu cliente (FIANI, 2002), o ativo é produzido de acordo com a necessidade especifica do cliente, desta maneira dificilmente foi revendido a outrem. Quanto maior a especificidade de ativos maiores serão os custos decorrentes das quebras contratuais, (MELZ; MARION FILHO, 2014 b). Porém quanto menos específicos forem os ativos, o mercado nesse caso é a forma mais eficiente de realizar transações, situação que ocorre quando há aumento da frequência da utilização do bens ou do produto (PEREIRA et al., 2014).

Williamson (1996) Fiani (2002), apresentam diferentes tipos de ativos específicos, sendo: 1) locacional, este relacionado ao custos de estocagem e transporte, procurando a mitigação desses custos; 2) Física, trata de característica do bem, design, onde o ativo pode ser feito para um trabalho específico e precise de características também especificas; 3) Capital humano, originado da expressão "aprender fazendo"; 4) Ativos dedicados, são bens produzidos sob encomendas; e 5) especificidade temporal, leva em consideração o tempo utilizados pelos indivíduos durante o processo de produção.

\subsection{Estruturas de governança}

O contrato é a unidade de análise básica dos custos de transação, os contratos de acordo com uma abordagem microeconômica, não envolvem custos, justo que estes desprezam os custos de elaborar e implementar contratos (FIANI, 2002). A economia dos custos de transação coloca a organização econômica como sendo um problema de contratos. Para se executar uma 


\section{Revista \\ UNEMAT de \\ Contabilidade}

v. 10, n. 19,2021

tarefa qualquer, há diversos modos de se organizar, a fim de que essas possam ser cumpridas (SILVA; WAQUIL, 2002).

Para ilustrar a escolha das firmas por uma determinada estrutura de governança, Williamson elaborou o esquema simplificado de contratos (Figura 1).

Figura 1 - Esquema simplificado de contratos

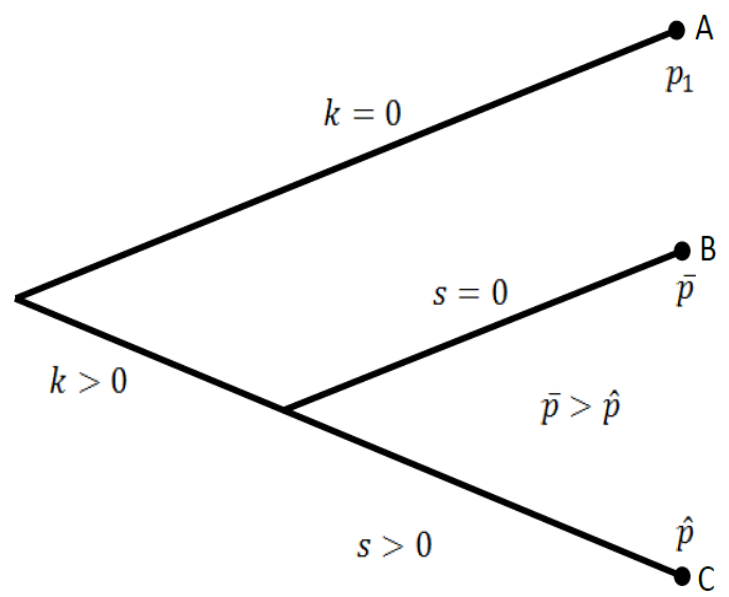

Fonte: Adaptado de Williamson (2012).

Nota: $k=$ ativos específicos; $s=$ salvaguardas; $p=\operatorname{preços;~} A=\operatorname{mercado} ; B=\operatorname{contratos} ; C=$ hierarquia.

O ponto A do esquema é o mercado de balcão ${ }^{1}$. O ponto B é a estrutura de contratos. $\mathrm{O}$ ponto $\mathrm{C}$ é a hierarquia. No mercado de balcão, não há ativos específicos (k) envolvidos, por isso não há necessidade de salvaguardas (s). Em B não incorre a inclusão de salvaguardas (s), desta maneira, o preço $(\bar{p})$ é maior. No ponto $\mathrm{C}$ existem as salvaguardas, quanto mais especifico o ativo for maior foi o número de salvaguardas desse contrato, reduzindo ações oportunistas e a incerteza. O preço $(\hat{p})$ tende a ser menor em transações contratuais em decorrência dos riscos menores em transações que envolvem mais ricos os preços foram maiores, quanto mais especifico o ativo for melhor se este for incorporado, ou seja, integrado verticalmente (MELZ et al., 2014; WILLIAMSON, 2012).

\section{METODOLOGIA}

Trata-se de uma pesquisa de campo (LAKATOS; MARCONI, 2017), qualitativa (FLICK, 2009), com característica descritiva (HERNÁNDEZ SAMPIERI; FERNÁNDEZ COLLADO; LUCIO, 2013), aplicada por meio de questionário com perguntar abertas e fechadas (VIEIRA, 2009), juntamente com escalas as quais foram aplicados nos escritórios de contabilidade de Nova Mutum- MT.

Segundo Flick (2009) a pesquisa qualitativa diz respeito ao uso de técnicas e métodos e pesquisa específica, nesse método existe a necessidade de caminhos para a aplicabilidade de técnicas que envolvem formular questões bem elaboradas e identificar bons códigos por

\footnotetext{
${ }^{1}$ Mercado balcão ou mercado spot, para autores como Abitante (2010) e Williamson (WILLIAMSON, 2012) é o mercado a vista ou mercado de produtos acabados prontos para a venda.
} 


\section{Revista \\ UNEMAT de \\ Contabilidade}

v. 10, n. 19,2021

exemplo. No método qualitativo a problemática é maior devido a área de aplicação e a flexibilidade que esta demanda, o que vem a influenciar as decisões perante cada caso.

Trata-se de uma pesquisa descritiva pois o estudo em questão trouxe a descrição dos escritórios, identificação dos custos e relatou as medidas que os escritórios participantes da pesquisa utilizam para prevenir-se de custos de transação, Beuren et al (2013). Para Gil (2012) a pesquisa descritiva é aquela que visa descrever características e estabelecer relações entre as variáveis, tendo como característica a utilização de técnicas de coletas padronizados.

Nesta pesquisa foi realizada entrevista estruturada. Segundo Cruz (2001) o procedimento mais recorrente em pesquisa de campo é a entrevista pois esta busca informações na fala dos agentes respondentes. A amostragem foi não probabilística por conveniência (VIEIRA, 2009) adquirida por meio de uma lista com os escritórios disposta no sítio eletrônico do CRC do estado de Mato Grosso (CRC-MT, 2019). O procedimento de bola de neve foi utilizados para localizar os escritórios (VINUTO, 2016) e por meio de tentativas de contato foram constatados 19 escritórios ativos no município.

Os questionários foram enviados no dia 17 de julho de 2019, porém até o final do mês a quantidade de questionários respondidos foi menor que a esperada, diante disso, houve intensificação nas cobranças, conseguindo na primeira quinzena do mês de agosto um número de questionários respondidos superior ao do mês anterior, havendo um total de 15 respondentes.
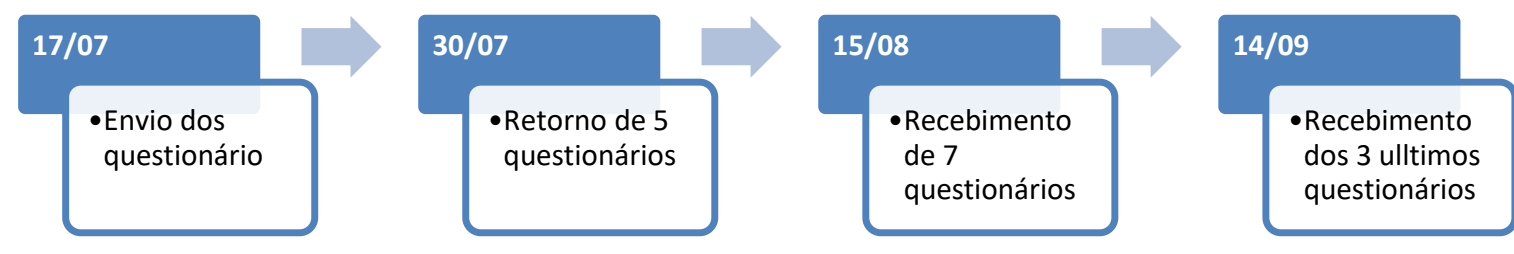

Antes do envio dos questionários, houve a solicitação dos e-mails via telefonema, após foram enviados os questionários, dado prazo de uma semana para a resposta, houve a visita in loco para recolhimento, quando alegado o não recebimento ou não visualização dos e-mails, o questionário era deixado em mãos, e programadas as datas para retirada.

A pesquisa se deu por meio de questionário constituído de perguntas direcionadas a um ou mais atores (de preferência os responsáveis, administradores ou gerentes dos escritórios) para que fosse respondido visando a resposta ao problema da pesquisa (VIEIRA, 2009). O procedimento para a análise de dados se deu por meio de tabelas, quadros, ocorrendo por meio de tabulação em planilha eletrônica e análise com tabelas de frequência e referência cruzada. As tabelas devem ser citadas no texto assim que o assunto for tratado e de conforme as normas do Instituto Brasileiro de Geografia e estatística (IBGE).

\section{RESULTADOS}

Os resultados foram estruturados em três seções. Na primeira são caracterizados os respondentes, na segunda são analisados os pressupostos comportamentais percebidos pelos entrevistados e na terceira são identificados os fatores que influenciam a adoção de medidas de prevenção dos custos de transação pelos entrevistados. 


\section{Revista

\subsection{Características dos escritórios participantes}

Nesta pesquisa foram obtidas 15 respostas dos escritórios de contabilidade. Três questões foram feitas para caracterizar os respondentes, sendo elas: 1) A quantos anos você atua no ramo de prestação de serviços contábeis?; 2) Aproximadamente quantos clientes são atendidos pelo seu escritório?; e 3) Qual o porte da sua empresa de prestação de serviços contábeis? A Tabela 1 apresenta a experiência dos respondentes e o número aproximado de clientes.

Tabela 1 - Estatística descritiva dos prestadores de serviços contábeis de Nova Mutum 2019

\section{Questão}

1) A quantos anos você atua no ramo de prestação de serviços contábeis?

2) Aproximadamente quantos clientes são atendidos pelo seu escritório?
Média Mínimo Máximo

$13,20 \quad 1 \quad 34$

$171 \quad 7 \quad 500$

Fonte: dados da pesquisa (2019)

E média os respondentes têm 13,20 anos de experiência sendo que o menos experiente tem 1 ano e o mais experiente tem 34 anos. O número médio de clientes é de 171, sendo que o menor deles tem 7 e o maior 500. A partir do tempo de experiência foram criadas duas categorias para classificar as respostas de acordo com a experiência. Foram elas: 1 - menos experientes; e 2- mais experientes. Sendo que os menos experientes são aqueles com até 10 anos e os mais experientes com 15 ou mais anos.

Quanto ao porte os respondentes informaram que 11 são Microempresa (ME), 2 são empresas de pequeno porte (EPP) e 1 é limitada (Ltda). Para evitar o risco de identificação desta empresa optou-se por criar 3 categorias com base nos percentis já que a caracterização de Ltda não se trata de porte mas do tipo societário. Até 50 clientes foram classificadas como pequenas, acima de 50 e com menos de 250 como medias e acima de 250 ou mais como grandes. Não necessariamente as empresas com o maior número de clientes estão classificadas em faixas de faturamento mais altas, já que algumas delas tem um número maior de clientes porém estão enquadras como ME. A tabela 2 apresenta o tamanho dos escritórios em relação a experiência desses respondentes.

Tabela 2 - Cruzamento das informações de experiência e porte dos respondentes, nova mutum, 2019.

\begin{tabular}{cccc}
\hline \multirow{2}{*}{ Tamanho } & \multicolumn{2}{c}{ Experiência } & \multirow{2}{*}{ Total Geral } \\
\cline { 2 - 3 } & 1-menos experiência & 2- mais experiência & \\
\hline 1- pequenas & 3 & 2 & 5 \\
2- médias & 2 & 1 & 3 \\
3- grandes & 2 & 4 & 6 \\
\hline
\end{tabular}


Total Geral 7

Fonte: dados da pesquisa (2019)

Dos escritórios classificados como pequenos 3 são menos experientes e 2 mais experientes, classificados como médios 2 são menos experientes e 1 mais experiente, dos grandes 2 são menos experientes e 4 mais experiente, diante disso pode-se dizer que os escritórios estão distribuídos uniformemente, não há grande diferença entre os números de entrevistados com menos ou com mais experiência e nem com relação ao tamanho.

\subsection{Pressupostos comportamentais de oportunismo e racionalidade limitada na visão dos contadores}

Na Tabela 3 é possível observar as respostas dos respondentes sobre a questão que identifica a presença de oportunismo entre os clientes.

Tabela 3- Responde a questão - 8) Sobre o comportamento dos seus clientes, é possível dizer que eles agem de forma oportunista?

\begin{tabular}{ccccc}
\hline Resposta & 1- pequenas & 2- medias & 3-grandes & Total Geral \\
\hline 1-todos são oportunistas & - & - & - & - \\
2 -sim, mas não todos & 4 & 4 & 5 & 13 \\
3-não, nenhum deles & 1 & & 1 & 2 \\
Total Geral & $\mathbf{5}$ & $\mathbf{4}$ & $\mathbf{6}$ & $\mathbf{1 5}$ \\
\hline
\end{tabular}

Fonte: dados da pesquisa (2019)

A maioria dos entrevistados afirma que alguns de seus clientes agem de forma oportunista, porém, não são todos. Há uma percepção geral de que afirmam que os clientes agem sim de forma oportunista, mas há exceções. Essa percepção dos respondentes se relaciona com os dados da tabela 4 confirmando que na opinião dos respondentes há presença do pressuposto de oportunismo.

Tabela 4- Percepção em relação ao pressuposto de oportunismo em relação aos clientes dos contadores de Nova Mutum.

\begin{tabular}{|c|c|c|c|c|c|}
\hline Meus clientes, em geral... & $\mathbf{N}$ & Mínimo & Máximo & Média & $\begin{array}{l}\text { Desvio } \\
\text { Padrão }\end{array}$ \\
\hline $\begin{array}{l}\text {...Deixam de compartilhar informações críticas } \\
\text { como exigido pelo nosso acordo }\end{array}$ & 14 & 1 & 5 & 2,79 & 1,188 \\
\hline $\begin{array}{c}\text {... exploram meus serviços não inclusos em } \\
\text { contrato. }\end{array}$ & 15 & 1 & 5 & 2,73 & 1,387 \\
\hline ... as vezes violam itens do acordo. & 15 & 1 & 4 & 2,27 & 1,100 \\
\hline $\begin{array}{c}\text {... não se preocupam quando passo por problemas } \\
\text { de adaptação de normas e legislações. }\end{array}$ & 15 & 1 & 5 & 3,00 & 1,512 \\
\hline $\begin{array}{c}\text {... não se esforçam nem cooperam com a } \\
\text { necessidade de atender as mudanças na } \\
\text { legislação }\end{array}$ & 15 & 1 & 5 & 3,07 & 1,100 \\
\hline ... me tratam de forma injusta na relação de troca. & 15 & 1 & 4 & 1,67 & 0,976 \\
\hline
\end{tabular}


$\begin{array}{lllllll}\text {... tentam por todos os meios reduzir o preço } & 15 & 1 & 5 & 2,67 & 1,291\end{array}$

Fonte: Dados da pesquisa (2019)

Na percepção dos contadores do município, em média, há pouco oportunismo na sua forma fraca por parte de seus clientes, mais próximo a 1 indica menor oportunismo e mais próximo a 5 existe oportunismo. Percebeu-se maior nível de oportunismo quanto a preocupação dos clientes em relação às adaptações e as mudanças na legislação, por meio do desvio padrão tem-se a indicativa de que há pouca divergência entre as respostas dos entrevistados, dessa forma há a percepção de oportunismo, porém na sua forma fraca (WILLIAMSON, 2012).

A Tabela 5 mostra a percepção dos respondentes sobre investimentos em Ativos Específicos e à Incerteza.

Tabela 5 - Relação de ativos específicos e incerteza na percepção dos escritórios de Nova Mutum, 2019.

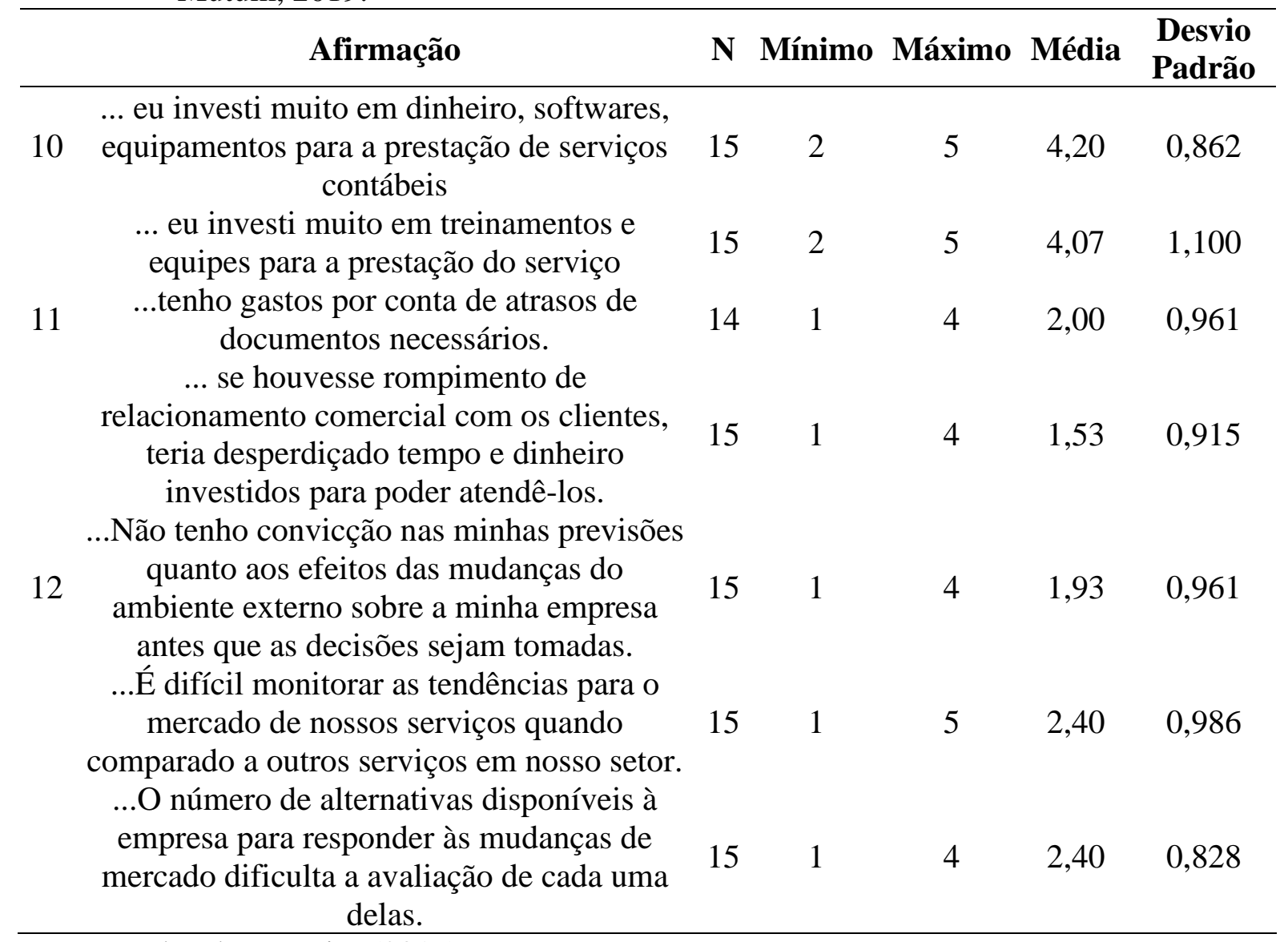

Fonte: Dados da pesquisa (2019)

Os respondentes percebem que investiram em ativos específicos, físicos (equipamentos) e humanos (treinamento), mas que não há especificidade temporal, mas também dizem que se caso houver rompimento com cliente esse investimento não seria totalmente perdido, logo, esses ativos não são tão específicos, não havendo exclusividade nas relações contratuais (FIANI, 2002), pois as condições nas quais atuam segundo os escritórios não são providas de incerteza já que o ambiente não sofre de maneira recorrente com possíveis 
eventos (SANTOS; CALÍOPE; COELHO, 2014). O desvio padrão apresentado indica que há pouca divergência entre as respostas dos entrevistados.

$\mathrm{Na}$ Tabela 6 foram respondidos quais os órgãos que o contador busca para obter informação sobre seus clientes.

Tabela 6- Órgãos buscados para adquirir informações dos futuros clientes dos escritórios de contabilidade de Nova Mutum, 2019.

\begin{tabular}{ccc}
\hline & $\begin{array}{c}\text { Quais órgãos são utilizados para buscar informações sobre seus } \\
\text { clientes para prevenir problemas futuros? }\end{array}$ & Resposta \\
\hline $1^{\text {o }}$ & Contador anterior & 9 \\
$2^{\text {o }}$ & Receita Federal & 8 \\
$3^{\text {o }}$ & Outros (Consultoria, Serasa, Indicação, Conversas) & 5 \\
$4^{\text {o }}$ & Conselho Regional de Contabilidade & 2 \\
& Total de respostas & 24 \\
\hline
\end{tabular}

Fonte: dados da pesquisa (2019).

Nota: Alguns respondentes responderam mais que uma alternativa.

Os órgãos mais procurados para prevenir os problemas futuros na prestação dos serviços contábeis são os contadores que prestavam o serviço anteriormente e a receita federal, porém, alguns utilizam meios de consultoria como o Serasa para obter mais informações, para responder essa questão alguns escritórios marcaram mais de uma alternativa, essas medidas utilizadas para prevenção (ex ante) reduzem custos futuros (ex post), (FIANI, 2002; WILLIAMSON, 2012). Santos (2011) constatou que 60\% dos escritórios prestadores de serviços contábeis participantes da pesquisa, buscam informação com o contador anterior e $16 \%$ buscam tais informações em órgãos de classe como o Sindicato dos Contabilistas de Curitiba (Sicontiba) e o CRCPR, em Nova Mutum -MT o percentual é de $37 \%$ para os respondentes que buscam o contador anterior, 33\% para os que buscam a receita federal e apenas $8 \%$ para os que buscam órgãos de classe como o Conselho Regional de Contabilidade (CRC).

A Tabela 7 mostra a frequência com que os escritórios costumam atualizar suas cláusulas contratuais, sendo as respostas $1=$ Nunca e $5=$ Sempre.

Tabela 7- Frequência de inclusão e/ou modificações em cláusulas contratuais dos escritórios de Nova Mutum, 2019.

\begin{tabular}{ccccccc}
\hline $\begin{array}{c}\text { Com que frequência sua empresa, inclui ou } \\
\text { modifica cláusulas contratuais, como as citadas } \\
\text { abaixo, para prevenção de custos futuros? }\end{array}$ & N & Mínimo & Máximo & Média & $\begin{array}{c}\text { Desvio } \\
\text { Padrão }\end{array}$ \\
\hline ... Datas e prazo nos serviços que foram realizados & 15 & 1 & 5 & 2,20 & 1,320 \\
$\quad$..Datas de coleta de documentos fiscais & 15 & 1 & 5 & 2,33 & 1,397 \\
$\quad \begin{array}{l}\text {..Datas de coletas de documentos contábeis } \\
\text {..Datas de coletas de documentos trabalhistas } \\
\text {... Com que frequência sua empresa costuma } \\
\text { revisar as cláusulas contratuais de prestação de }\end{array}$ & 15 & 15 & 1 & 5 & 2,40 & 1,404 \\
$\quad$ Serviços? & & & 5 & 2,87 & 1,552 \\
\hline
\end{tabular}

Fonte: dados da pesquisa (2019). 


\section{Revista

Os contadores de Nova Mutum não percebem muita incerteza e consideram seus investimentos em ativos não muito específicos (Tabela 5). Eles confiam nos seus clientes e percebem pouco oportunismo (Tabela 4) por isso eles não revisam com frequência as cláusulas e salvaguardas, depois de fazer o contrato, quase nunca fazem ajustes ou revisões nas cláusulas contratuais, isso significa redução de custos de elaboração, revisão dos contratos. Farina et al (1997), diz que quanto mais frequente, menor seus custos de transação, porém, como o contexto no qual estão inseridos não apresenta grande incerteza, e por isso, eles não vêm a necessidade de revisar com frequência os contratos. Santos (2011) elaborou uma questão para verificar a frequência de inclusão de cláusulas referentes a datas e prazos dos serviços, e datas de coletas dos documentos. Entre 44\% $(17+27)$ dos respondentes de Curitiba disseram nunca e 30\% $(17+13)$, responderam raramente.

\subsection{Fatores que influenciam os escritórios a utilizar medidas preventivas dos custos de transação}

Para responder o objetivo específico $\mathrm{n}^{\mathbf{0}} 3$ foram realizadas perguntas sobre as medidas utilizadas pelos escritórios para a redução dos custos de transação, a tabela 8 apresenta as respostas em relação a frequência com que assumem essas penalidades.

Tabela 8 - Respostas a questão 5 'Com que frequência sua empresa tem assumido penalidades decorrentes dos atos dos seus clientes? (1=Nunca; 5=Sempre), amostra de 15 escritórios de contabilidade em Nova Mutum, 2019.

\begin{tabular}{cccccccc}
\hline Penalidades & $\begin{array}{c}\text { 0-Não } \\
\text { respond } \\
\text { eu }\end{array}$ & 1-Nunca & $\begin{array}{c}\mathbf{2 -} \\
\text { Poucas } \\
\text { vezes }\end{array}$ & $\begin{array}{c}\text { 3-Às } \\
\text { vezes }\end{array}$ & $\begin{array}{c}\text { 4-Quase } \\
\text { sempre }\end{array}$ & $\begin{array}{c}\text { 5- } \\
\text { Sempre }\end{array}$ & $\begin{array}{c}\text { Total } \\
\text { Geral }\end{array}$ \\
\hline $\begin{array}{c}\text { Juros e Multas } \\
\text { Custas }\end{array}$ & - & 5 & 6 & 2 & 1 & 1 & 15 \\
$\begin{array}{c}\text { Trabalhistas } \\
\text { Custas Judiciais }\end{array}$ & 5 & 8 & 2 & - & - & - & 15 \\
$\begin{array}{c}\text { Honorários } \\
\text { Advocatícios }\end{array}$ & 5 & 9 & 1 & - & - & - & 15 \\
$\begin{array}{c}\text { Despesas de } \\
\text { Cartórios }\end{array}$ & 4 & 6 & 4 & 1 & - & - & 15 \\
Outros & 8 & 5 & 1 & 1 & - & - & 15 \\
\hline
\end{tabular}

Fonte: Dados da pesquisa (2019).

Quando questionados sobre a frequência com que assumem penalidades decorrentes de seus clientes, a maioria dos escritórios afirmou não sofrer penalidades. No que se refere a juros e multas 6 dos escritórios disseram que poucas vezes assumiram, e apenas 1 respondeu que assumia sempre. Oito dos escritórios disseram nunca assumir custos com multas trabalhistas, e 9 disseram não ter penalidades com custas judiciais e honorários advocatícios. Quanto às despesas de cartórios, 6 dos respondentes disseram nunca assumir e 4 que assumiam poucas vezes e apenas um que por vezes assumiam. Na pesquisa de Santos (2011) mesmo não havendo tanta proteção em relação aos custos de transação seus clientes raramente assumem fontes desses custos sendo $54 \%$ (juros e multas), $23 \%(10+13)$ foram obrigadas a assumir sempre, ou quase sempre, multas e juros. Já no trabalho de Borges et al (2012) mais de 70\% das empresas 
prestadoras de serviços nunca tiveram que assumir penalidades, 53,33\% dos entrevistados afirmaram que assumem com frequência juros e multas e 68,90\% assumem com frequência outros encargos decorrentes dos atos de clientes.

O quadro 4 traz os fatores que levam os escritórios a assumir custos de transação e ainda o que fazem para que possam se prevenir.

Quadro 4 - Comparativo dos fatores e das medidas preventivas utilizadas pelos escritórios de contabilidade em Nova Mutum 2019.

\begin{tabular}{|c|c|}
\hline $\begin{array}{l}\text { 6) Quais os fatores que os levam a adotar medidas } \\
\text { de prevenção aos custos de transação? }\end{array}$ & $\begin{array}{l}\text { 16) Quais as medidas utilizadas para prevenir os } \\
\text { custos de não cumprimento de contratos? }\end{array}$ \\
\hline Rescisões contratuais & Indenização \\
\hline Não respondeu & Não respondeu \\
\hline $\begin{array}{l}\text { Dossiê de não conformidade para apresentar para } \\
\text { fundo de reserva }\end{array}$ & Reuniões de abertura de \% de quebra de contrato \\
\hline Não respondeu & Não respondeu \\
\hline $\begin{array}{l}\text { Orientar a todos os clientes as bases corretas e legais, } \\
\text { deixando-os cientes do que o erro pode causar por } \\
\text { isso feito contrato entre cliente e escritório numerando } \\
\text { quais os nossos deveres e obrigações assim como o } \\
\text { deles }\end{array}$ & $\begin{array}{l}\text { Visita ao cliente para tratar especificamente do } \\
\text { referido assunto }\end{array}$ \\
\hline $\begin{array}{l}\text { Como o cliente nos pesquisa, pesquisamos o mesmo. } \\
\text { Evitamos assim transtornos futuros. }\end{array}$ & $\begin{array}{l}\text { Reunião com o cliente, demonstrando os trabalhos } \\
\text { realizados, nossa seriedade }\end{array}$ \\
\hline Não respondeu & Não respondeu \\
\hline Penalidades arcadas pelo escritório & Alerta verbalmente no início do contrato \\
\hline $\begin{array}{l}\text { A leitura do contrato com o cliente e entrega de uma } \\
\text { via, contato, visitas com o cliente }\end{array}$ & Multas ao cliente \\
\hline Redução de custos e maior transparência ao cliente & $\begin{array}{l}\text { Relacionamento próximo, cobranças com todos os } \\
\text { documentos possíveis: notas fiscais, boletos, contrato, } \\
\text { comunicados, avisos periódicos, reuniões, todos os } \\
\text { mecanismos possíveis }\end{array}$ \\
\hline $\begin{array}{l}\text { Além de juros e multas que jogam para } \\
\text { responsabilidade da empresa, tem também ex- } \\
\text { funcionários que não realizavam trabalho correto }\end{array}$ & Não realizar mais os serviços \\
\hline $\begin{array}{l}\text { Custos decorrentes dos clientes, não assumimos, } \\
\text { repassamos para o mesmo }\end{array}$ & Acordo verbal \\
\hline $\begin{array}{l}\text { Como o ramo de contabilidade presta muita obrigação } \\
\text { acessória ao fisco e outros órgãos fiscalizadores, } \\
\text { estamos sujeitos a falhar em algumas estas. Por este } \\
\text { motivo este é o fator que mais nos preocupa quando a } \\
\text { custos que o escritório pode ter e que podem afetar } \\
\text { gravemente o financeiro, dependendo da intensidade } \\
\text { das penalidades de cada obrigação acessória. }\end{array}$ & Até o momento nenhuma \\
\hline Monitorar as rotinas na escrita & Monitoramento frequente \\
\hline Cumprimento rigoroso dos prazos das obrigações & $\begin{array}{l}\text { Tudo que está no contrato é cumprido mesmo que } \\
\text { necessário ir até o cliente }\end{array}$ \\
\hline
\end{tabular}

Fonte: dados da pesquisa (2019).

Do lado esquerdo do Quadro 4 são apresentados os fatores que, segundo os respondentes, os levam a adotar medidas preventivas dos custos de transação. As principais segundo eles, são os custos, as rescisões contratuais e as obrigações a serem cumpridas pelos escritórios. Do lado direito estão dispostas as medidas que os escritórios utilizam ou passaram a utilizar em para evitar essas penalidades. As mais citadas foram, a adoção de acordos, inclusão de salvaguardas como cláusulas de indenização, e monitoramento para verificação do 


\section{Revista \\ UNEMAT de \\ Contabilidade}

v. 10, n. 19,2021

comprimento dos contratos e reuniões com os clientes. O lado direito do quadro evidencia tanto os custos ex ante, tais como cláusulas contratuais, quanto os ex post, como reuniões e visitas aos clientes, conforme descrito por Williamson (2012), como medida de prevenção em relação a rescisão contratual e cumprimento das obrigações e redução dos custos arcados pelos escritórios de um modo geral são utilizadas penalidades e monitoramentos e reuniões acordos verbais com seus clientes.

A tabela 9 traz a as formas mais comuns de evasão praticada pelos clientes dos escritórios em Nova Mutum nas áreas fiscal e trabalhista, sendo 1= a resposta principal e 2, 3, $4=$ secundarias.

Tabela 9- Resposta a questão 7 'Quais formas mais comuns de evasão fiscal praticadas pelos clientes das empresas prestadoras de serviços contábeis, em cada uma das áreas?' em Nova Mutum, 2019

\begin{tabular}{|c|c|c|c|c|c|c|c|}
\hline Área & Condição & $\begin{array}{c}\text { Não } \\
\text { respond } \\
\text { eu } \\
\end{array}$ & $\mathbf{1}$ & 2 & 3 & 4 & $\begin{array}{l}\text { Total } \\
\text { Geral }\end{array}$ \\
\hline \multirow{4}{*}{ Fiscal } & Venda sem nota Fiscal & - & 13 & 2 & - & - & 15 \\
\hline & Compra sem nota Fiscal & 2 & 2 & 4 & 6 & 1 & 15 \\
\hline & Omissão de Receita & - & 6 & 5 & 3 & 1 & 15 \\
\hline & $\begin{array}{c}\text { Auxílio nas Práticas Financeiras } \\
\text { das Empresas }\end{array}$ & 4 & 2 & 1 & 2 & 6 & 15 \\
\hline \multirow{4}{*}{ Trabalhista } & Registro de Salário a menor & - & 2 & 5 & 4 & 4 & 15 \\
\hline & Pagamento de salário por fora & 2 & 5 & 7 & 1 & - & 15 \\
\hline & $\begin{array}{c}\text { Não recolhimento dos impostos } \\
\text { FGTS/INSS }\end{array}$ & 1 & 3 & 4 & 7 & - & 15 \\
\hline & Outros. & 12 & - & - & - & 3 & 15 \\
\hline
\end{tabular}

Fonte: Dados da pesquisa (2019).

Nota: Na tabela, $1=$ a resposta principal e 2, 3, 4= secundarias.

Divididos por área, na área fiscal quando da venda sem nota fiscal 87\% dos escritórios disseram ser a forma mais comum de evasão a venda sem nota fiscal. Apenas $13 \%$ escritórios disseram ser de importância secundária, já na área trabalhista a forma mais comum e indicada como principal por $34 \%$ dos entrevistados foi o pagamento de salário por fora, $46 \%$ dos escritórios disseram que esta seria de importância secundária.

Os resultados da pesquisa de Santos (2011) evidenciam que, venda e compra sem nota fiscal - somam $60 \%$. Na área trabalhista, pagamento de salário "por fora" e registro de salário a menor - somam 59\%, "Os resultados demonstram que os empresários têm uma visão de redução de custos que os põem em risco e também o contador responsável pela escrituração contábil e fiscal (NCC, Lei n. ${ }^{\circ}$ 10.406/2002), (SANTOS et al., 2011, p. 42)."

A Tabela 10 apresenta a frequência com que os escritórios fazem a revisão dos contratos firmados, segundo os tamanhos deles.

Tabela 10- Frequência de revisão dos contratos nos Escritórios de contabilidade de Nova Mutum 2019

\begin{tabular}{ccccc}
\hline Respostas à Questão 13 & 1- pequenas & 2- médias & 3- grandes & Total Geral \\
\hline 1-nunca & - & - & - & - \\
2- poucas vezes & 2 & 1 & 2 & 5
\end{tabular}




\section{Revista UNEMAT de Contabilidade}

3- várias vezes

4- sempre

Total Geral

\section{2}

1

5

Fonte: dados da pesquisa (2019)

Em geral respostas referentes as medidas de prevenção dos custos de transação que os escritórios utilizam foram semelhantes, independente do tamanho do escritório. Desse modo, percebe-se que o tamanho não interfere na frequência de revisão dos contratos e que todos eles fazem revisão de contrato, mesmo que poucas vezes (33\%). Em Tangará da Serra $71,11 \%$ das empresas fazem a revisão das cláusulas contratuais de prestação de serviços e $28,89 \%$ não fazem revisão (BORGES et al., 2012).

Na divisão dos custos de transação em ex ante e ex post, a revisão de contrato é característica dos custos ex post, pois trata da manutenção durante a vigência do acordo para garantir o cumprimento contratual (FIANI, 2003).

A tabela 11 traz as condições nas quais as empresas fazem revisões nas cláusulas contratuais.

Tabela 11 - Resposta a questão 18 'Em que condições sua empresa faz revisão nas cláusulas contratuais?' nos escritórios de contabilidade de Nova Mutum, 2019.

\begin{tabular}{ccc}
\hline & Condições & Respostas \\
\hline $1^{\text {o }}$ & Alteração do regime tributário & 12 \\
$2^{\text {o }}$ & Alteração de preços & 6 \\
$3^{\text {o }}$ & Diante das mudanças dos planos econômicos & 4 \\
$4^{\text {o }}$ & Outros (alteração de sociedade, novas obrigações e serviços, aumento & 3 \\
& de trabalho) & 25 \\
\hline
\end{tabular}

Fonte: dados da pesquisa (2019)

Nota: Alguns respondentes responderam mais que uma alternativa.

Os respondentes de Nova Mutum quando questionados sob quais condições faziam revisões contratuais, $24 \%$ disse ser quando há alteração dos valores, $48 \%$ disseram revisar cláusulas diante das mudanças no regime tributário de seus clientes e $16 \%$ dos escritórios disseram alterar diante das mudanças em planos econômicos e $12 \%$ disse revisar clausulas diante de outras situações como alteração de sociedade, novas obrigações e serviços e aumento de trabalho, a revisão dos contratos é decorrente da incapacidade do ser humano de prever todas as situações sendo assim uma peça importante para o cumprimento de um acordo, (ZYLBERSZTAJN, 1995). No trabalho realizado por Santos (2011), constatou-se que 86\% dos respondentes não revisam cláusulas diante dessa condição de alteração no regime tributário do cliente. Na pesquisa de Borges et al (2012) verificou-se que há alteração contratual em relação a alterações de valores e de alteração de regime tributário, mas que apenas 6,67\%, fazem alteração contratual diante das mudanças dos planos econômicos. Sobre a inclusão de salvaguardas nos contratos a tabela 12 , traz as medidas utilizadas para clientes que buscam os serviços contábeis, mas que não dão garantia de permanência a curto prazo.

Tabela 12- Resposta a questão 19 'Como sua empresa protege de clientes que constituem uma empresa no seu escritório e depois mudam outro escritório para a contabilização 
dentro de curto período de tempo?' nos escritórios de contabilidade de Nova Mutum, 2019.

\begin{tabular}{ccc}
\hline & Medidas & Respostas \\
\hline $1^{\text {o }}$ & Conta com a boa fé do cliente & 7 \\
$2^{\text {o }}$ & Cláusula contratual de permanência Mínima & 4 \\
$3^{\text {o }}$ & Faz acordo verbal & 3 \\
$4^{\text {o }}$ & Outros (avisos, não se previnem) & 2 \\
& Total Geral & 16 \\
\hline
\end{tabular}

Fonte: dados da pesquisa (2019)

Nota: Alguns respondentes responderam mais que uma alternativa.

A maioria dos respondentes demostram confiança nos clientes, $43,75 \%$ dos escritórios contam com a boa fé do cliente, $18,75 \%$ faz acordo verbal com seus clientes, $12,5 \%$ dizem ser por meio de avisos de antecedência ou não se prevenirem para esse tipo de custo e $25 \%$ dizem fazer a inclusão de salvaguardas de permanência mínima, no trabalho de Santos (2011), verificou-se que dos respondentes $37 \%$ confiam na boa fé, $16 \%$ acordam verbalmente e $34 \%$ fazem a inclusão de permanência mínima. Borges et al (2012), observaram que 42,22\% das empresas contam com a boa fé dos clientes, 15,56\% fazem acordo verbal, $20 \%$ utilizam cláusula contratual de permanência mínima.

Ainda no que se refere a prevenção dos custos de transação, a tabela 13 apresenta como os escritórios orientam seus clientes em relação a Evasão físcal.

Tabela 13- Resposta a questão 20 'Como sua empresa orienta seus clientes em relação à Evasão fiscal?’ nos escritórios de contabilidade de Nova Mutum, 2019.

\begin{tabular}{lcc}
\hline & Métodos de orientação & Respostas \\
\hline $1^{\text {o }}$ & E-mail & 10 \\
$2^{\text {o }}$ & Reuniões & 7 \\
$3^{\text {o }}$ & Outros & 5 \\
$4^{\text {o }}$ & Folhetos e Cartilhas & 2 \\
$5^{\text {o }}$ & Palestras & 2 \\
& Total Geral & 26 \\
\hline
\end{tabular}

Fonte: dados da pesquisa (2019)

Nota: Alguns respondentes responderam mais que uma.

De acordo com os respondentes as orientações ocorrem 38,46\% por e-mail, 26,92\% por meio de reuniões e 7,69\% por folhetos e cartilhas assim como por meio de palestras também 7,69\% e outros 19,23\%, nesse foram citados: visitas periódicas; e conversas com o cliente e mensagens. A pesquisa realizada em Tangara da Serra por Borges et al. (2012), verificou que $17,78 \%$ orientam por e-mail, $55,56 \%$ por meio de reuniões e $24,44 \%$ orientam em palestras. O trabalho de Santos (2011) verificou em sua pesquisa que $78 \%$ (somatória) orientam por meio de reuniões ou e-mails. A medida de orientação utilizada para prevenir que possam vir a ocorrer custos de transação são considerada custos ex ante, para que não sofram penalidades por conta de seus clientes existem gastos por parte dos escritórios, já que esse trata de custos de negociar e salvaguardar o acordo firmado (WILLIAMSON, 2012).

A tabela 14 apresenta os controles utilizados pelas empresas para prevenção de prejuízos futuros em relação a falto de documentos. 


\section{Revista

Tabela 14- Resposta a questão 21 'Quais controles são utilizados pela sua empresa para prevenir-se de prejuízos futuros por falta de documentos?' nos escritórios de contabilidade de Nova Mutum, 2019.

\begin{tabular}{lcc}
\hline & Medidas & Respostas \\
\hline $1^{\text {o }}$ & Confirmação de e-mail recebidos & 13 \\
$2^{\text {o }}$ & Protocolos Manuais & 13 \\
$3^{\text {o }}$ & Protocolo (Softwares) & 7 \\
$4^{\text {o }}$ & Outros (whatsapp) & 2 \\
& Total Geral & 35 \\
\hline
\end{tabular}

Fonte: dados da pesquisa (2019)

Nota: Alguns respondentes responderam mais que uma alternativa.

Dos controles que os escritórios utilizam para prevenção desses custos, $37,14 \%$ utilizam a confirmação de e-mails, o mesmo percentual se aplica aos protocolos manuais, $20 \%$ utilizam protocolos (softwares) e 5,71\% dizem utilizar também aplicativo de mensagens. Em Tangará da Serra 48,89\% utilizam confirmação de e-mail recebidos, 24,44\% Protocolos Manuais, 13,33\% Protocolo (Softwares) (BORGES et al., 2012). Na pesquisa de Santos (2011), 30\% dos respondentes utilizam a confirmação de recebimentos por e-mail e $29 \%$ utilizam os protocolos manuais.

\section{CONSIDERAÇÕES FINAIS}

Quanto às características dos escritórios, identificou-se que esses têm em média 13,20 anos, 171 clientes e não há grande diferença entre os números de entrevistados com menos ou com mais experiência e nem com relação ao tamanho.

Nota-se que os escritórios de maneira geral confiam nos seus clientes e percebem pouco oportunismo por isso eles não revisam com frequência as cláusulas e salvaguardas, depois de fazer o contrato e quase nunca fazem ajustes ou revisões em todos ou qualquer dos itens isso significa redução de custos de elaboração, revisão dos contratos. A maioria dos respondentes demostram confiança nos clientes em relação ao tempo de serviço prestado, $43,75 \%$ dos escritórios contam com sua boa-fé e $25 \%$ dizem fazer a inclusão de salvaguardas de permanência mínima.

Os escritórios concordam que há oportunismo, porém na forma fraca e maioria dos escritórios afirmou não assumir penalidades decorrentes da atitude de seus clientes, desse modo fazem as revisões com pouca frequência.

As condições nas quais os escritórios disseram fazer revisões contratuais foram, 24\% para alteração dos valores, $48 \%$ na revisão de cláusulas diante das mudanças no regime tributário de seus clientes e $16 \%$ diante das mudanças em planos econômicos e $12 \%$ disse revisar clausulas diante de outras situações como alteração de sociedade, novas obrigações e serviços e aumento de trabalho, o tamanho não interfere na frequência de revisão dos contratos, todos a fazem, mesmo que poucas vezes.

Em relação aos ativos específicos e a incerteza do contexto qual estão inseridos os escritórios percebem que investiram em ativos tanto humano como material, porém os ativos não são tão específicos já que as condições nas quais atuam segundo os escritórios não são providas de incerteza. 


\section{Revista

O objetivo da pesquisa foi identificar as medidas que os escritórios de contabilidade de Nova Mutum utilizam para prevenir custos de transação. Os dados permitiram verificar que as empresas prestadoras de serviços contábeis de Nova Mutum, se previnem de custos de transações adotando acordos, incluindo salvaguardas como cláusulas de indenização, e monitoramento para verificação do comprimento dos contratos e reuniões com os clientes. Conclui-se que as medidas mais utilizadas em Nova Mutum para prevenção dos custos de transação ex post são confirmações de e-mails e protocolos tanto manuais como por softwares, previnem-se contra a evasão fiscal por parte dos clientes por meio de e-mails reuniões e visitas aos clientes.

É preciso manter cautela quanto as relações com clientes, pois não se pode prever tudo o que pode acontecer, levando em consideração a racionalidade limitada e o oportunismo de seus clientes, que por haver possibilidade de que ocorram, já é o bastante para a inclusão de salvaguardas, assim quando firmado um contrato deve haver clausulas que sirvam de amparo a empresa. O papel do profissional é de suma importância, este deve ter uma visão ampla das atuações da organização, e estar constantemente atento a mudanças de legislação e a frequência de mudanças contratuais e efetuar sempre que possível as revisões e incluir cláusulas de proteção sempre que necessário, assim podendo reduzir seus custos ex ante e tentando evitar prejuízos futuros com a inclusão de salvaguardas e manutenções contratuais (ex post).

Sugere-se em futuras pesquisas analisar os principais motivos que levam as empresas a integrar verticalmente a área contábil para a empresa, quais os principais motivos de mantê-la dentro de sua hierarquia, pela especificidade dos ativos ou informações, maior controle dos contratos, as medidas utilizadas podem ser mais eficazes e custos que podem ser menores.

\section{REFERÊNCIAS}

ABITANTE, K. G. Co-integração entre os mercados spot e futuro: evidências dos mercados de boi gordo e soja. Revista de Economia e Sociologia Rural, v. 46, n. 1, p. 75-96, 2010.

BEUREN, I. M. et al. Como Elaborar Trabalhos Monográficos em Contabilidade. 3. ed. São Paulo: Atlas S.A., 2013.

BORGES, O. R. et al. Medidas de prevenção de custo de transação resultantes de evasão fiscal de cliente das Empresas Prestadora de Serviços Contábeis (EPSCs) em Tangará da Serra MT. Revista Unemat de Contabilidade, v. 1, n. 2, 2012.

CÁRDENAS, L. Q.; LOPES, F. D. A formação de alianças estratégicas: uma analise a partir da teoria da dependência de recursos e da teoria dos custos de transação. Cadernos EBAPE, v. 4, 2006.

COASE, R. H. The Nature of the Firm. Economica, v. 4, n. 16, p. 386-405, nov. 1937.

FARINA, E. M. M. Q.; AZEVEDO, P. F. DE; SAES, M. S. M. Competitividade: mercado, Estado e organização. São Paulo: Singular, 1997.

FIANI, R. Teoria dos Custos de Transação. In: KUPFER, D.; HASENCLEVER, L. (Eds.). . Economia Industrial: fundamentos teóricos e práticas no Brasil. Rio de Janeiro: Elsevier, 2002. p. 267-286.

FIANI, R. A natureza multidimensional dos direitos de propriedade e os custos de transação. Economia e sociedade, Campinas, v. 2, n. 1, p. 185-203, 2003.

FLICK, U. Introdução à pesquisa qualitativa. 3. ed. Porto Alegre: Artmed, 2009. 
HERNÁNDEZ SAMPIERI, R.; FERNÁNDEZ COLLADO, C.; LUCIO, M. DEL P. B. Metodologia de Pesquisa. Porto Alegre: Penso, 2013.

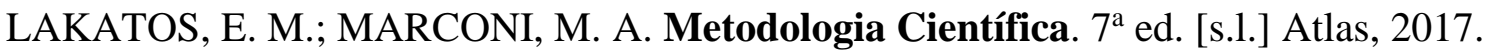

MELZ, L. J. et al. Análise das estruturas de governança e transações na suinocultura em Nova Mutum-MT. Congresso da Sober, 2014.

MELZ, L. J.; MARION FILHO, P. J. Economia dos Custos de Transação: uma contribuição da Contabilidade Gerencial. Congresso da SOBER. Anais...Goiânia: SOBER, 2014Disponível em: 〈http://icongresso.itarget.com.br/tra/arquivos/ser.4/1/2856.pdf>

MILGROM, P.; ROBERTS, J. Economics, organizations \& management. São Paulo: Pearson Prentice Hall, 1992.

MIRANDA, WENDER F. et al. A economia dos custos de trasação através do desenvolvimento da reputação favoravel. p. 1-17, 2001.

NETO, O. DA C. Pesquisa Social. Teoria, Método e criatividade. 18. ed. Petrópolis: Vozes, 2001.

PEREIRA, A. J. et al. A empresa e seu ambiente de interação: os limites da Teoria dos Custos de Transação e o alcance da Teoria Institucionalista Evolucionária. Economia e sociedade, Campinas, v. 23, n. 50, p. 33-61, 2014.

SANTOS, A. R. DOS et al. Empresas Prestadoras de Serviços Contábeis (EPSCs): medidas de prevenção de custos de transação resultantes de evasão fiscal de clientes. 190, p. 33-47, 2011.

SANTOS, J. G. C. DOS; CALÍOPE, T. S.; COELHO, A. C. D. Teorias da Firma como Fundamento para a formulação das Teorias Contábeis. Encontro da ANPAD - EnANPAD, 38, p. 1-16, 2014.

SARTO, V. H. R.; ALMEIDA, L. T. DE. A teoria dos custos de transação: uma análise a partir das críticas evolucionistas. Revista Iniciativa Econômica, v. 2, n. 1, 2015.

SILVA, A. A. DA; BRITO, E. P. Z. Incerteza, racionalidade limitada e comportamento oportunista : um estudo na indústria brasileira. Ram, Rev. Adm. Mackenzie, v. 14, n. 1, p. 176-201, 2013.

SILVA, L. X. DA; WAQUIL, P. DABDAB. Análise Do Complexo Agroindustrial Fumageiro Sul-Brasileiro Sob O Enfoque Da Economia Dos Custos De Transação. Economia, 2002.

TECNICAS, A. B. DE N. ABNT NBR 14724 Informação edocumentação- Trabalhos academicos- Apresentação. Norma Brasileira, v. 3, p. 11, 2011.

VIEIRA, S. Como elaborar qauestionarios. São Paulo: Atlas, 2009.

WILLIAMSON, O. E. The economic institutions of capitalism. New York: Free Press, 1985.

WILLIAMSON, O. E. The mechanisms of governance. Oxford: Oxford University Press, 1996.

WILLIAMSON, O. E. As instituições econômicas do capitalismo: firmas, mercados, relações contratuais. São Paulo: Pezco, 2012.

WILlIAMSON, O. E. . Calculativeness, Trust, and Economic Organization Source: The Journal of Law \& Economics. The Journal of Law \& Economics, 1993. 


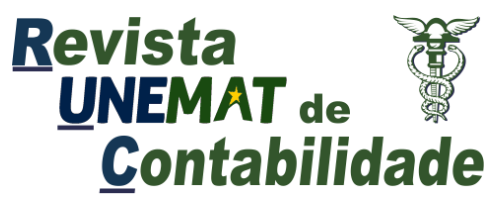

v. 10, n. 19,2021

ZYLBERSZTAJN, D. Estruturas de governança e coordenação do agribusiness: uma aplicação da nova economia das instituições. [s.l.] Universidade de São Paulo, 1995.

ZYLBERSZTAJN, D.; SZTAJN, R. A economia e o direito de propriedade: diálogos FEA \& Largo São Francisco. n. 1937, p. 281-286, 2002. 